\title{
Advances in design theories of high-speed railway ballastless tracks
}

\author{
Xueyi LIU*, Pingrui ZHAO, Feng DAI \\ MOE Key Laboratory of High-Speed Railway Engineering, Southwest Jiaotong University, Chengdu 610031, China
}

\begin{abstract}
The design theories of the ballastless track in the world are reviewed in comparison with the innovative research achievements of high-speed railway ballastless track in China. The calculation methods and parameters concerning train load, thermal effect, and foundation deformation of high-speed railway ballastless track, together with the structural design methods are summarized. Finally, some suggestions on the future work are provided.
\end{abstract}

Key words: high-speed railway; ballastless track; design theory

C 2011 JMT. All rights reserved.

\section{Introduction}

tructure forms and design theories of ballastless $\checkmark$ tracks vary across the world due to the different development backgrounds. In Japan, the slab track was typically laid on the solid foundation such as a bridge or tunnel at first, and then gradually developed to the soil subgrade afterwards. It adopts the unit design that takes into account the effect of train load. The German ballastless track was first laid on the soil subgrade and then on the foundation of bridges and tunnels. Its continuous structure involves the consideration of thermal effects. The early ballastless track in China was mainly laid in tunnels with the chief concern being the influence of train load. With the increasing application of ballastless track, a relatively general design theory and a structural system have been gradually formed after the innovative research with high-speed railway ballastless track.

This paper reviews the calculation methods and parameters as well as the structure design procedures, and briefly introduces the advance in the design theories, of ballastless track based on the innovative research achievements in China. Finally, some suggestions on the future work are provided, including fatigue properties under the coupling action of train and temperature load, durability, long-term dynamic properties, and maintenance mechanics of the ballastless track.

\footnotetext{
Received Jul. 17, 2011; revision accepted Aug. 29, 2011

${ }^{*}$ Corresponding author. Tel.:+86-28-87600243

E-mail: xyliu@home.swjtu.edu.cn (X.Y. LIU)

(C) 2011 JMT. All rights reserved

doi: 10.3969/j.issn.2095-087X.2011.03.002
}

\section{Overview of ballastless track design theories}

In the design of Japanese slab track, the train load effect is a primary concern. Using the elastic design method, the security during the manufacturing, hoisting, and constructing of the slab track is maximized. As seriously damaged CA mortar at the slab corner and the slab warping caused by temperature gradients emerged, the uneven support caused by warping is considered in the analysis [1]. In the baseplate design, in accordance with the limit state method, the train load and the subgrade's uneven settlement are considered together with the influence of weather conditions, concrete contraction, and construction.

German developed its ballastless track by borrowing the design concept and method of pavement engineering [2]. Most has longitudinally continuous structure, and temperature load and concrete contraction are the main factors to be considered in the design. The reinforcement is located near the neutral axis and does not bear the train load. The effect of train load and temperature gradient is resisted by the rupture strength of the concrete.

In China, the early monolithic roadbed track, whose structure design mainly considers the train load, was applied in the tunnels with good foundation condition and little temperature variation. The structural design of the Suining-Chongqing railway took into account the effect of uneven foundation deformation and temperature load [3-4]. Following systematic research on the ballastless track, the design theory based on the allowable stress method was created with full consideration of train load, temperature, and foundation deformation effect. 
In general, the design theory of ballastless track in different country was relevant to its own construction environment and structure evolution. The design theory proposed in different periods could meet the construction requirements for different types of ballastless track.

\section{Calculation of train load stress}

The track supports the train load and guides the vehicle operation. The calculation of train load stress must be considered in the ballastless track design. The elastic foundation beam model [5-6] is mainly used for calculation of the load stress in the traditional track structure. The model can be solved using the multilayer composite beam theory on the elastic foundation [7-10] according to the complexity and analysis requirement of the track structure. In Germany, however, the Eisenmann theory [11-13] was adopted to calculate the stress of the rail structure under the train load. In this theory, rail is regarded as an infinite beam on the elastic foundation to calculate the support reaction of the fastener; the multilayer structure is translated into a monolayer one according to the connection status of the structural layer, and then the internal force and displacement of the converted monolayer structure under the action of fastener force is calculated using the infinite beam on the elastic foundation and Westgaard's stress function.

To sum up, the main components are treated as flexural members in the train load design of ballastless track in China and Japan. This is because the ballastless track design was originally developed based on the traditional design methods for ballast track that put an emphasis on simulation of the force properties of main components and the generality of analysis method. In Germany, however, the design theory and parameters selection of ballastless track were developed from the experience of highway concrete pavement design; thus, its structural difference in ballastless track can also be attributed to heritance of the traditional design theory.

In accordance with the structural characteristics that the rail and the sleeper are cross-supported on the elastic foundation in the ballast track, the cross beam model on the elastic foundation [14-15] was developed on the basis of the elastic foundation beam model, and can also be used for the stress calculation of the ballastless track [16] once the values of the model parameters are determined. Thanks to the development of the computing technology, the solid finite element model [17-19] can be employed to obtain the particular stress state inside the ballastless track structure.

As the major supporting structure of the ballastless track, the track slab (or bed slab) and baseplate (or supporting layer), whose deflections under the train load are far smaller than their thicknesses, have a far smaller size in the vertical direction than in the longitudinal or lateral direction. This feature conforms to the structural characteristics of the elastic plate. Consequently, the elastic plate [20] is generally adopted for simulation and analysis of the supporting structure of ballastless track. The rail, a slender structure, is reasonably simulated by the beam model, while the fastener and the intermediate elastic layer, as well as the foundation below, are simulated with different kinds of springs. As a result, a beam-plate model of ballastless track on elastic foundation [21-23] is built as shown in Fig. 1.

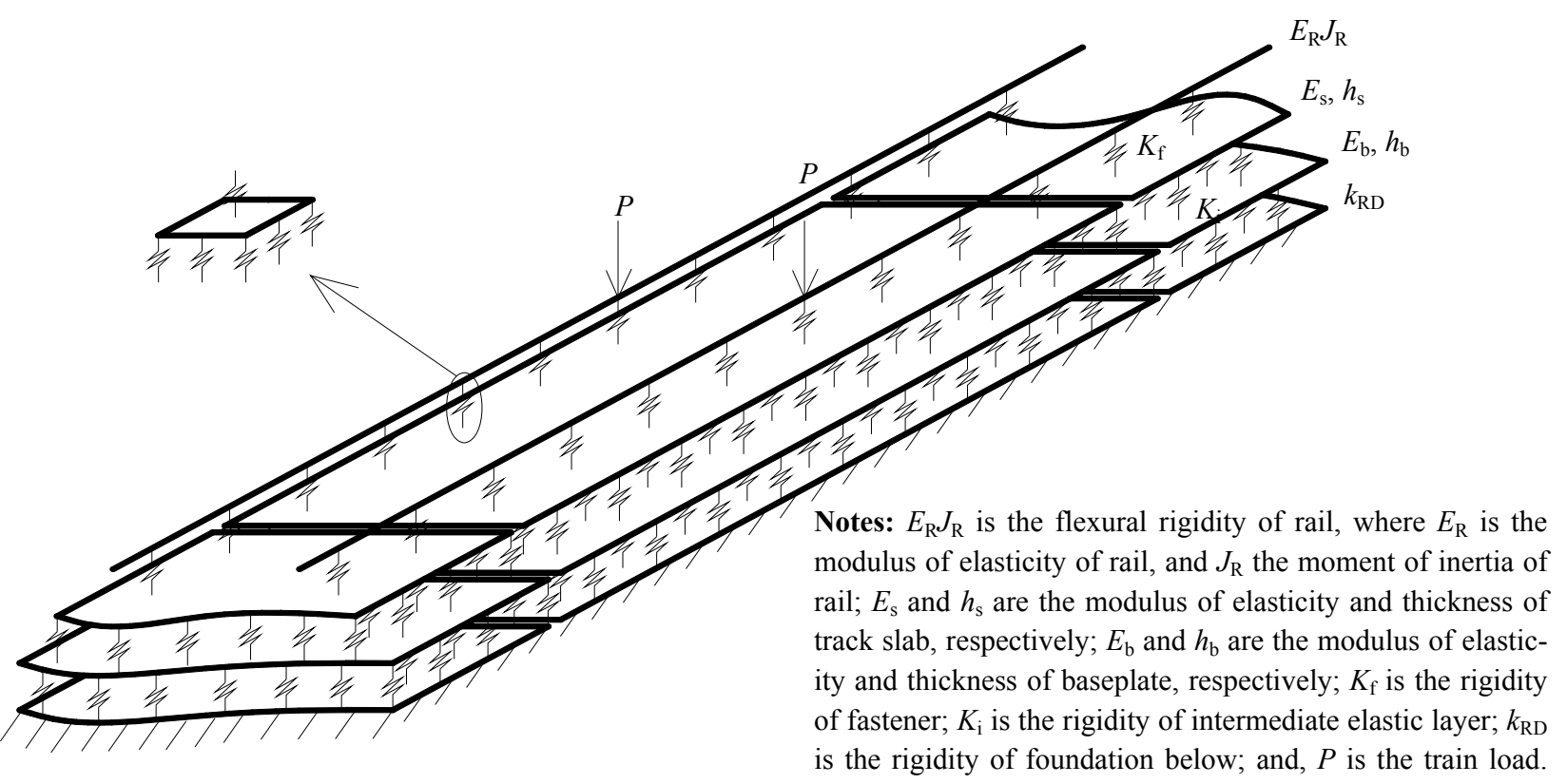

Fig. 1 The elastic foundation beam-plate model of ballastless track 
The load stress of the track slab (or bed slab) and the baseplate (or supporting layer) in the longitudinal and lateral directions can be obtained by exerting a vertical train load on the rail. This avoids the calculation in the longitudinal and lateral directions separately in the multilayer elastic foundation beam model. Moreover, the computational accuracy [7] is higher than that via the composite beam model or the cross beam model, and the computing workload is less than that via the solid finite element model.

The design wheel load of the Japanese slab track takes into consideration the wheel load variation due to wheel tread damage and tolerates three times the static wheel load. In fatigue checking, the allowable wheel load is 1.45 times the static wheel load. On the basis of the allowable value of the derailment coefficient, the design lateral force was determined, and the lateral force for fatigue checking takes half of the design lateral force. In the Germany ballastless track design, the load takes the UIC71 with the dynamic coefficient of 1.5 and the unbalance loading coefficient of 1.2. In China, the dynamic coefficient is based on the results of dynamic tests and simulation calculations of the ballastless track, and the design wheel load can be three times the static wheel load. Based on the design parameters and operation conditions of the ballastless track on the passenger dedicated line (PDL) in China, the coupling dynamics of train and track system is applied to the statistic analysis. Considering the construction and maintenance conditions of the ballastless track in China, it is suggested that the constant effect train load be up to 1.5 times the static load [24].

The Winkler foundation is used to support the ballastless track, and the diameter of the bearing plate has a significant influence on the foundation coefficient. The smaller the diameter, the larger the foundation coefficient [1]. However, when the diameter $D$ is not less than $76 \mathrm{~cm}$, the change in the diameter has little influence on the foundation coefficient. As for the ballastless track, the supporting area of the track slab or the supporting layer is relatively large. Thus, for simplicity, the trial value of the bearing plate with a diameter of $76 \mathrm{~cm}$, namely $k_{76}$, can be used for calculations. When the subgrade compaction capacity is represented by the deformation modulus, the layered elastic system mechanics [3] can be applied to analyze the displacement of the subgrade surface with the even load of the rigid bearing plate; thus, deducing the supporting rigidity of the subgrade surface [25].

Within every bearing layer of the ballastless track, the substructure is generally weaker than the upper structure, and may readily crack under the train load if plain concrete or cement stabilized materials are applied. Once cracking, the bending moment is not readily trans- ferred at the crack location, resulting in a reduction in the entire rigidity and the modulus of elasticity. Therefore, the reduced elastic modulus is used for calculation [26]. As for the reinforced concrete structure, the reinforcement is helpful to improve the flexural rigidity of the structural layers. However, due to the possible cracking, the transmission of the bending moment at the cracked location may be weakened. Consequently, only the concrete elastic modulus is used for calculation, without consideration of the influence of the reinforcement and crack.

\section{Calculation of temperature stress}

The ballastless track is exposed to the atmosphere. With changes in external temperature, the temperature in every structural layer will vary. Once the deformation of the ballastless track due to the changing temperature is restrained, the temperature stress will occur inside the structure. The ambient temperature variation with an effect on the ballastless track includes the yearly temperature variation and daily temperature variation. In addition, the contraction of concrete will cause distortion, which is equivalent to decreasing the temperature load acting on the concrete.

The design of the continuous ballastless tracks represented by Rheda, Züblin, and Bögl in Germany attach great importance to the temperature effect. In order to limit the width of the temperature cracks within the admissible range and maintain the state of incomplete cracks [27], the ratio of reinforcement in the slab should reach $0.8 \%-0.9 \%$, according to the German Ballastless Track Design Specification. As a result, the width of cracks is limited within $0.5 \mathrm{~mm}$. From the viewpoint that the sum of the minimum stress of the reinforcement with the slab cracking and the bending stress increment under the dynamic load must be less than the reinforcement fatigue limit to guarantee the service life, it is supposed that the longitudinal ratio of the reinforcement must be larger than $1.0 \%$, so as to meet the demands of crack width and service life.

The Japanese slab track design adopts unit structure, and temperature variation has little influence on the track slab. Thus, temperature effect is not considered in the design. Nevertheless, warping displacement of the track slab is found in tests, where the track slab is in a state of being incompletely supported. Therefore, to address the variation properties of the track slab due to temperature, a series of theoretical and experimental research has been conducted [4].

As for the continuous slab structure, under the action of concrete contraction and decreasing temperature, concrete may easily crack, causing a stress redistribution of the reinforcement and concrete inside the slab. In or- 
der to guarantee security and utility, it is necessary to control the reinforcement stress and crack width.

The continuous slab shows different stress and variation properties at various tension stages. Before the concrete cracks, the concrete deformation is coordinated by the reinforcement. When the tensile stress of the concrete reaches its tensile strength, it will crack and stop working, which leads to the bond damage adjacent to the cracks. At this moment, the plain section hypothesis does not fit any more, and the reinforcement at the crack location bears all the axial force. When the axial force increases to the yield strength of the reinforcement, the concrete is cracked severely without bearing the tension. All the axial force is born by the reinforcement, such that the reinforcement yielding becomes the limiting condition of the slab in tension. The cracking axial force of the continuous slab depends on the tensile strength of the concrete and the sectional area of the slab. The amount of reinforcement has little influence on the cracking axial force, while the ultimate bearing capacity completely depends on the yield strength and the area of the reinforcement. In order to avoid cracking, the minimum ratio of reinforcement of the continuous slab should be specified.

The cracking in the continuous slab go through two phases: incomplete cracking and complete cracking. At the stage of incomplete cracking, the amount of cracks increases with the increasing load, and the maximum crack width remains basically unchanged. At the stage of complete cracking, the number of cracks remains unchanged, while its width increases with the increasing load. In order to limit the crack width, the cracking should be controlled at the stage of incomplete cracking. In the cases of incomplete cracking, the maximum temperature force inside the slab depends on the tensile strength and the sectional area of the concrete. The temperature force calculated with the design tensile strength is regarded as the common temperature force (main force). And the temperature force calculated with the standard tensile strength is taken as the maximum temperature force for checking in design. Refs. [28-29] elaborated the different expressions of fracture interval, cracking width and reinforcement stress at different stages of cracking, and the relevant design measures have been put forward.

As for the unit bed slab structure, the temperature force of the slab is influenced by the longitudinal resistance of the fastener at the top and the frictional resistance at the bottom, as well as the displacement limitation of the convex plate. The classification of the unitary and continuous structure depends on whether the temperature force leads to the full-section cracking of the slab.

\section{Calculation of warping stress}

The external environment will affect the temperature and humidity of the concrete slab. The influence of external environment gradually weakens with the depth from slab surface. The uneven distribution of temperature and humidity inside the slab leads to its warping deformation. When the deformation is restrained by the bottom friction, dead load, stop blocks, and train load, the warping stress occurs.

According to the German railway code, it is hypothesized that the slab in the vertical direction has a linear temperature gradient of $50{ }^{\circ} \mathrm{C} / \mathrm{m}$. In the temperature field test of the ballastless track on Suining-Chongqing railway, the temperature gradient [30] of the track before laid is about $52.6-68.4{ }^{\circ} \mathrm{C} / \mathrm{m}$ and the temperature gradient of the slab track in the longitudinal direction on the Jialingjiang bridge is approximately $40-80{ }^{\circ} \mathrm{C} / \mathrm{m}$ [31], with a large dispersion, but all larger than that of $50{ }^{\circ} \mathrm{C} / \mathrm{m}$ in Germany.

In terms of geography and climate conditions, China has severely cold areas, cold areas, and temperate areas. Referring to the recommended value of the temperature gradient in the field of highway pavement, in consideration of the structure characteristics of the ballastless track, we advise that the maximum positive temperature gradient of the uppermost structure of the ballastless track in China be $80-85^{\circ} \mathrm{C} / \mathrm{m}, 85-90{ }^{\circ} \mathrm{C} / \mathrm{m}$ and 90 $95{ }^{\circ} \mathrm{C} / \mathrm{m}$ for severe cold area, cold area and temperate area, respectively, and that the temperature gradient distribute linearly in the vertical direction. The effect of temperature gradient can be neglected in the substructure. The negative temperature gradient can be half the maximum positive temperature gradient.

According to the statistical data about the temperature and the temperature gradient variation in Germany, studies have been conducted to analyze the slab stress state under the action of the temperature gradient, especially the slab with smaller lateral size whose warping deformation is not restrained completely. The calculation model with discontinuous supporting was utilized to calculate the warping stress [32] under the action of dead load and temperature gradient.

The warping stress and displacement of the slab track in different constraint conditions were analyzed by finite element theory. The results show that the stronger the restraint acting on the track slab, the more the warping deformation is resisted, and the closer the warping stress in the slab track to that of an infinite slab. The restraints acting on the track slab include the track dead load, the restraint of the continuous long rails, and the train load acting on the rails. Because of the large supporting coefficient in the ballastless track supporting system, the 
loading restraint of the track slab, due to the limitation of the loading magnitude and position, shows many differences. For convenience, no matter for the unitary or the continuous structure, the warping stress of the ballastless track in the longitudinal or lateral direction is calculated in accordance with the infinite slab.

\section{Calculation of foundation deformation effect}

Ballastless track will be influenced remarkably by the large rigidity of the track slab or the bed slab once uneven deformation occurs at the foundation.

In the Japanese slab track base design, the maximum settlement displacement $(\delta)$ occurs at the mid-point and at the ends of the baseplate with the half-wave sinusoid of $\delta=20 \mathrm{~mm}$ at the service and fatigue state, together with that of $\delta=30 \mathrm{~mm}$ at the ultimate state. Based on the deformation relevance, the rigidities at different locations of the settlement area with an interval of $5 \mathrm{~m}$ are calculated to ensure the settlement of the baseplate under the dead load reaches the designed uneven settlement. Then the additional bending moment [33] due to foundation deformation of the baseplate is calculated. Germany has a concept of "zero settlement" that uneven settlement must not occur. Thus, there is no need to consider the uneven settlement effect in design. Although high-speed railways have developed rapidly in China, uneven settlement is also inevitable at the subgrade-bridge transitional sections and high embankment. In order to ensure the proper operation of ballastless track, the influence of uneven settlement of foundation should be considered in the design of ballastless track in China.

Because of the large rigidity of ballastless track, when there is uneven settlement, the slab will have the same deformation as the foundation, which can be viewed as a forced displacement of the slab structure. In this case, the bending moment of the slab under the action of foundation deformation equals to the product of its flexural rigidity and the uneven deformation curvature.

\section{Design of ballastless track structure}

The bearing structures of the ballastless track mainly include plain concrete, reinforced concrete, and prestressed reinforced concrete. The plain concrete structure is usually applied to the tunnels with good foundation and small ambient temperature variation. In this case, the slab will not crack [34] under the action of train load and environmental factors. Under the common foundation conditions, the slab may readily crack with the influences of foundation deformation, train load, and environmental factors. Thus, it is necessary to add reinforcements to limit the crack development. As for the continuous reinforcement concrete slab, because the temperature stress is the main influencing factor, reinforcements are laid near the neutral axis to limit the crack width and crack interval of the track slab. For the sections with severely weak foundations, the bending moment in the slab is usually large. In order to limit the crack width, we need to thicken the slab or improve the foundation, which results in high costs. In that case, placing reinforcements in top and bottom layers can help the track slab bear more bending moment [35-36]. To limit the crack width and improve the structure durability, steel fiber concrete has been increasingly used in the ballastless track structure [37-38]. In cold areas, prestressed reinforced concrete structure is often adopted for decreasing the freezing injury.

The allowable stress method and the ultimate state method are generally utilized in the concrete structure design. As the Japanese track slab was designed as reinforced concrete structure originally, the allowable stress method is adopted provided that the track slab concrete under the action of bending moment conforms to the hypothesis of plane mechanism, while the tensile stress of the concrete in the tension zone is negligible. The allowable stress of the reinforcement depending on the repeated loading times varies with different design wheel load and structure types. In the cold areas, anti-freezing measures should be taken. Considering factors such as construction and costs, the prestressed reinforced concrete structure [39] designed by partial limit state theory is applied.

For the German ballastless tracks like Rheda and Züblin, the longitudinal reinforcements are placed in the continuous slab for the purpose of controlling the crack types and width. The width of the slab is determined by the Westergaard's stress equations and the allowable compressive stress of the subgrade surface. Determination of the slab thickness follows the principle that the stress caused by temperature gradient and load is less than the flexural strength of the slab concrete. The supporting layer is composed of plain concrete probably with cracks or is the hydraulic supporting layer structure. The load stress should be checked within the permissible limit to determine the modulus of elasticity of the supporting layer.

Ballastless track, laid on the elastic foundation under the long-term repeated action of train load and environmental change, is of band structure distinct from the structures like bridge and building. In order to ensure its high accuracy and high stability, the rail structure is required to work in an elastic condition under the action of train load and surrounding factors. Therefore, we suggest that the ballastless track structure design adopts the 
allowable stress method for the innovative research of high speed railway in China.

During the design, it is assumed that every plane cross-section remains a plane under the action of the bending moment. The normal stress of the concrete in the compression zone takes a triangle pattern, the tensile strength of the concrete in the tension zone is neglected for the reinforced concrete components, and the normal stress of the concrete in the tension zone also takes a triangle pattern for prestressed reinforced concrete components. Under the action of axial force, the temperature stress of the continuous ballastless track, which may cause cracking, is resisted by the reinforcement, and the plane assumption is invalid.

Because the method for calculating the load effect, especially under the action of bending moment is different from the calculation model for structure design, a correction factor is introduced to eliminate the difference in the obtained results. The specific design flow for the ballastless track structure is shown in Fig. 2.

As for the unit ballastless track, the reinforcement is mainly based on the load bending moment and the effect temperature force is negligible. For the continuous ballastless track, concrete contraction and temperature decreases are the main factors influencing the reinforcement. The load combinations for the different kinds of ballast- less track on diverse foundations are listed in Table 1.

The daily temperature has a periodic variation, leading to a periodic variation in temperature stress and warping stress. Nevertheless, the maximum temperature gradient and the maximum temperature force do not appear everyday. Especially for the continuous ballastless track, the maximum temperature force only occurs at the critical state when a new crack appears. When the crack is stabilized, the temperature force is mostly less than the maximum temperature tension. Therefore, the maximum temperature tension is unlikely to appear in the continuous ballastless track, and it can be regarded as a kind of load combination and checked independently.

The subgrade of PDLs is required to be designed and constructed under the concept of "zero settlement". However, uneven settlement is easy to occur at the transitional section between subgrade and the structures such as bridge, tunnel or culvert. And the probability of the uneven settlement within a small range occurring to common sections is quite low. Therefore, the uneven settlement of subgrade should be combined as an additional force with a low probability of occurrence. Under the train load, a bridge has bending deformation which coincides with the train load. Consequently, the bridge bending deformation should be combined as the main force the same as the train load.

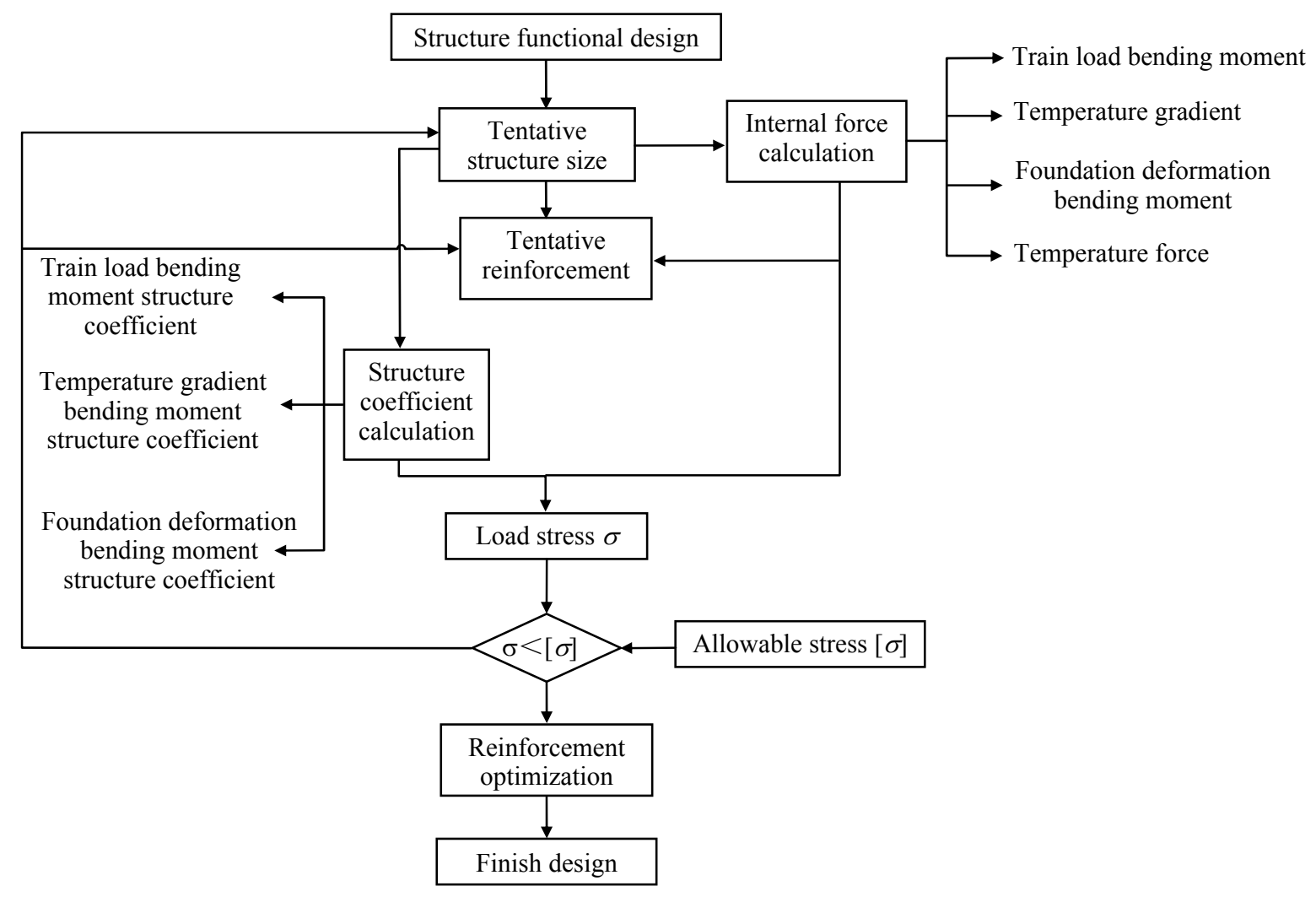

Fig. 2 Design flow for the ballastless track structure 
Table 1 Suggested load combinations for different types of ballastless tracks

\begin{tabular}{|c|c|c|c|c|}
\hline \multirow{2}{*}{ Type } & & \multicolumn{3}{|c|}{ Load combination } \\
\hline & & On subgrade & On bridge & In tunnel \\
\hline \multirow{3}{*}{$\begin{array}{l}\text { Unit ballastless } \\
\text { track }\end{array}$} & \multirow{2}{*}{ Main force } & $3 M_{\text {Train }}$ & $3 M_{\text {Train }}$ & $3 M_{\text {Train }}$ \\
\hline & & $1.5 M_{\text {Train }}+M_{\Delta T}$ & $1.5 M_{\text {Train }}+M_{\Delta T}+M_{\mathrm{D}}$ & - \\
\hline & $\begin{array}{c}\text { Main force } \\
+ \text { additional force }\end{array}$ & $1.5 M_{\text {Train }}+M_{\Delta T}+M_{\mathrm{D}}$ & - & - \\
\hline \multirow{4}{*}{$\begin{array}{l}\text { Continuous } \\
\text { ballastless track }\end{array}$} & \multirow{3}{*}{ Main force } & $3 M_{\text {Train }}$ & $3 M_{\text {Train }}$ & $3 M_{\text {Train }}$ \\
\hline & & $F_{\mathrm{T}, \max }$ & $F_{\mathrm{T}, \max }$ & $F_{\mathrm{T}, \max }$ \\
\hline & & $1.5 M_{\mathrm{Train}}+M_{\Delta T}+F_{\mathrm{T}}$ & $1.5 M_{\text {Train }}+M_{\Delta T}+M_{\mathrm{D}}+F_{\mathrm{T}}+F_{\mathrm{D}}$ & $1.5 M_{\text {Train }}+F_{\mathrm{T}}$ \\
\hline & $\begin{array}{c}\text { Main force } \\
+ \text { additional force }\end{array}$ & $1.5 M_{\text {Train }}+M_{\Delta T}+M_{\mathrm{D}}+F_{\mathrm{T}}$ & $1.5 M_{\text {Train }}+M_{\Delta T}+M_{\mathrm{D}}+F_{\mathrm{T}}+F_{\mathrm{B}}+F_{\mathrm{D}}$ & - \\
\hline
\end{tabular}

Note: $M_{\text {Train }}$ denotes the bending moment caused by train load, $M_{\Delta T}$ denotes the bending moment caused by temperature gradient, $M_{\mathrm{D}}$ denotes the bending moment caused by foundation deformation, $F_{\mathrm{T}, \max }$ denotes the maximum temperature force, $F_{\mathrm{T}}$ denotes the temperature force, $F_{\mathrm{D}}$ denotes the axial force caused by foundation deformation, and $F_{\mathrm{B}}$ denotes the braking force.

According to the load combinations shown in Table 1, one should decide whether the edge stress of the supporting layer in the ballastless track exceeds its cracking stress. If the edge stress is lower than the cracking stress, then the supporting layer of the concrete will not crack, and reinforcement is unnecessary or should be placed in accordance with the structure. If the edge stress is higher than the cracking stress, then the supporting layer will crack. Especially for the continuous ballastless track, full-section cracking is likely to occur. At the moment, all the concrete in the tension zone at the cracking location under the action of bending moment stops working, and all the tension is resisted by the reinforcement. Nevertheless, the concrete between two cracks in the tension zone is still functioning, which leads to the variation of sectional flexural rigidity and neutral axial. The flexural rigidity of the cracked slab is decreased sharply. A thinner slab with a higher concrete grade will have a smaller flexural rigidity after cracked.

The flexural rigidity used for the load stress calculation is the one with the supporting layer's full section sharing the stress. However, during the design the concrete in the tension zone is supposedly out of operation completely, from which some error will occur and there is a need for revision.

According to the elastic foundation beam theory, the bending moment of the foundation beam under the concentrated load (train load) is directly related to the coefficient of elasticity of the foundation and the flexural rigidity of the foundation beam. The bending moment of the foundation beam is directly proportional to the $1 / 4$ power of its flexural rigidity. Similarly, the bending moments of the slab caused by temperature gradient and foundation deformation are directly proportional to its flexural rigidity. Thus, the correction factor of the bending moment caused by train load, temperature gradient and foundation deformation can be obtained.

\section{Conclusions and suggestions}

Ballastless track, with the merits of good ride comfort, high stability and little maintenance, has become the main type of the rail structure. The design concepts of the ballastless track are different in different countries: the factors considered in design and the calculation methods vary greatly with each other. This paper has summarized and analyzed calculation and design methods for ballastless track in the world. Based on the reinnovation research results of the ballastless track in China, relatively general design concepts and methods for ballastless track were put forward tentatively, which guided the design of ballastless track on the SuiningChongqing test section, the Wuhan-Guangzhou passenger dedicated line, the Lanzhou-Urumchi No.2 double line, as well as the reference diagram design of the slab track and the double block track.

Although, a type of structure with little maintenance, the ballastless track has many conditions during operation. Therefore, the design theory of ballastless track still needs further study. The future work may involve the following:

(1) Research on the fatigue properties under the coupling action of train and temperature load. Train load and temperature load are two kinds of loads repeatedly acting on the ballastless track. The statistical characteristics of train load and temperature load, especially the fatigue properties under different loads and their cou- 
pling action, should be studied to provide a basis for predicting the fatigue life of ballastless track.

(2) Research on the durability of ballastless track. The ballastless track is a composite structure composed of many kinds of materials. Under the combined action of environment and train load, different kinds of materials have different degradation curves, and the damage in one component will influence the durability of the whole structure. Therefore, a systematic method should be applied to the durability research of ballastless track, to realize a design concept of little maintenance.

(3) Research on long-term dynamic properties. Under the long-term combined action of train load induced vibration and natural environment, the function of the components of ballastless track is likely to degrade gradually. Consequently, the dynamic characteristics of ballastless track, and the safety and stability of train will be influenced. An analysis model of ballastless track with damage should be established for research on the long-term dynamic properties of ballastless track.

(4) Research on maintenance mechanics. At the beginning of the construction of ballastless track, some conditions have already occurred because of the errors in design and construction. Thus far, there is lack of a systematic, intensive study on the causes of diseases and the countermeasures. The intensive study on disease mechanism, maintenance standard, maintenance time, maintenance method, and the influence of maintenance on track and train will lay a good foundation for the maintenance work of ballastless track.

\section{Acknowledgements}

This work was supported by the National Natural Science Foundation of China (No. 51008258), and the Fundamental Research Funds for the Central Universities (No. SWJTU09BR038).

\section{References}

[1] Y.X. Wei, Y.J. Qiu, Research on the subgrade surface stiffness of ballastless track of high-speed railway, Journal of Railway Engineering Society, 2010(7): 15-20 (in Chinese).

[2] L. Bernhard, Developments in road pavement construction and railway track technology for a sustainable surface transport infrastructure, In: The Emerging Frontiers of Transportation and Development in China, Chengdu, 2009.

[3] D.Z. Zheng, D.C. Feng, Mechanics of Layered Elastic System, Harbin: Harbin Institute of Technology Press, 2001: 126-133 (in Chinese).

[4] Ando Satoshi, Loading-deformation characteristics of slab track with temperature variation, Railway Summary Report, 1989, 10(3): 2-9.
[5] Q.C. Wan, Y.G. Lu, Stress Calculation of New Sub-rail Foundations, Beijing: China Railway Publishing House, 1987: 15-45 (in Chinese).

[6] C. Esveld, Modern Railway Track, 2nd ed., Zaltbommel: MRT Productions, 2001: 71-73.

[7] Y.X. Liu, X.F. Chen, Two analytical methods of slab track structures. Urban Mass Transit, 2007(6): 3234,66 (in Chinese).

[8] C.Y. Qi, Research of soil subgrade slab track structures strength calculation, Railway Standard Design, 2006(2): 26-28 (in Chinese).

[9] L. Sun, Double-block ballastless track design of WuGuang passenger railway, Railway Standard Design, 2006(Sup.): 155-158 (in Chinese)

[10] S. Yoshihiko, New Track Mechanics, trans. Y. Xu, Beijing: China Railway Publishing House, 2001: 238-240 (in Chinese).

[11] J. Eisenmann, G. Leykauf, Slab track for railways, In: Concrete Calendar 2000, Berlin: Verlag Ernst \& Sohn, 2000: 10-15 (in German).

[12] J.J. Fan, Modern Railway Track, Beijing: China Railway Publishing House, 2000: 43-51 (in Chinese).

[13] J. Eisenmann, The dimension of a type of slab track, Railway Engineering, 1991, 42(3): 116-118, 120-122, 124 (in German).

[14] Q.D. Yue, F.X. Jiang, X.G. Li, A study on mechanical model of two-level crossing superposed beam system for section track structure, Railway Standard Design, 2002(12): 1-4 (in Chinese).

[15] S.Q. Li, S.J. Duan, J.W. Wang, et al., Track structure model of elastic supported grillage girder, Engineering Mechanics, 2001(Sup.): 508-513 (in Chinese).

[16] J.W. Wang, S.J. Duan, S.Q. Li, High-speed railway slab track structure static analysis, Engineering Mechanics, 2002(Sup.): 290-293 (in Chinese).

[17] C.X. Liu, W.M. Zhai, Elementary research on problem of slab's intensity by means of finite element analysis, Journal of Railway Engineering Society, 2001(1): 24-26 (in Chinese).

[18] L. Gao, M.N. Ma, D.M. Wang, Mechanic characteristic research of ballastless track structures on bridge with linear motion actuator delivery system, Railway Standard Design, 2007(7): 5-7 (in Chinese).

[19] C.X. Li, C.H. Li, Z.H. Kou, Mechanics analysis of slab track on soil foundation, Railway Engineering, 2005(7): 88-90 (in Chinese).

[20] P.R. Zhao, X.Y. Liu, Dynamic characteristic analysis and parameter study of slab track, Railway Engineering, 2004(5): 48-50 (in Chinese).

[21] P.R. Zhao, Y.A. Zhang, X.Y. Liu, et al., Beam-plate model on the elastic foundation of ballastless track, China Railway Science, 2009(3): 1-4 (in Chinese).

[22] J. Ren, Preliminary research and design of slab track, Railway Standard Design, 1996(6): 25-28 (in Chinese).

[23] Q.C. Wang, Design and Construction of Slab Track, Chengdu: Southwest Jiaotong University Press, 2002: 52-56 (in Chinese).

[24] C.B. Cai, P. Xu, Dynamic analysis of key design parameters for ballastless track of high-speed railway, 
Journal of Southwest Jiaotong University, 2010, 45(4): 493-497 (in Chinese).

[25] P. Xu, C.B. Cai, Theoretical calculation of the supporting stiffness of the subgrade surface in ballastless track and its application, China Railway Science, 2010(1): 2125 (in Chinese).

[26] P.R. ZHAO, X.Y. LIU, Reduced elastic modulus of cracked support layer in twin-block ballastless track, Journal of Southwest Jiaotong University, 2008, 43(4): 459-464 (in Chinese).

[27] Rail. ONE GnmH, Rheda 2000 Crack width calculation according to DIN 1045-1, Ingolstaedter, 2005.

[28] P.R. Zhao, X.Y. Liu, Thermal stress calculation method research of continuous slab, Railway Standard Design, 2008(10): 6-8 (in Chinese).

[29] P.R. ZHAO, X.Y. LIU, Thermal stress calculation method and parameter analysis of continuous slab, Railway Engineering, 2008(11): 81-85 (in Chinese).

[30] S.R. Wang, Study on Temperature Stress for Ballastless Track Slab [Dissertation]. Chengdu: Southwest Jiaotong University, 2007 (in Chinese).

[31] R.S. Yang, Experimental report of track static test on Jialing river bridge, Chengdu: Southwest Jiaotong University, 2007: 21-25 (in Chinese).

[32] J. Eisenmann, G. Leykauf, Concrete Carriageways,
Munchen: Ernst\&Sohn, 2003: 22-59 (in German).

[33] Japan Railway Construction Public Corporation Morioka Branch Office, Design Calculation of RC Subgrade Engineering, $t=300$ with Detail Design of Northeast Trunk Line, RC Subgrade Engineering, Japan, 1999.

[34] A. Faeh, M. Gloor, T. Gerber, Optimised ballastless track systems, In: IABSE Symposium, Antwerp, Belgium, August 2003: 52-60.

[35] C. Esveld, V. Markine, Use of expanded polystyrene (EPS) sub-base in railway track design, In: IABSE Symposium, Antwerp, Belgium, August 2003: 14-15.

[36] J.M. Zwarthoed, V.L. Markine, C. Esveld, Slab track design: flexural stiffness versus soil improvement, In: Proceedings of Rail-Tech Europe 2001 Conference, Utrecht, April 2001: 1-22.

[37] V. Henke, H. Falkner, SFRC for jointless railway tracks, In: IABSE Symposium, Antwerp, Belgium, August 2003: 46-51.

[38] T. Takahashi, F. Sekine, T. Horiike, et al., Study on the applicability of short fiber reinforced concrete to precase concrete slabs for slab track, Quarterly Report of RTRI, 2008, 49(1): 40-46.

[39] Japan Railway Construction Public Corporation Morioka Branch Office, Design Calculation of Northeast Trunk Line, Slab Design of PRC Structure A-55C, Japan, 1999.

(Editor: Junsi LAN) 